OPEN ACCESS

$$
\begin{array}{r}
\text { Edited by: } \\
\text { Luca Fiori, }
\end{array}
$$

Reviewed by:

Zhidan Liu,

China Agricultural University, China

Uwe Schröder,

Technische Universität Braunschweig,

Germany

${ }^{*}$ Correspondence:

Thomas François Robin

thomas.cognac@gmail.com

Specialty section: This article was submitted to Bioenergy and Biofuels,

a section of the journal

Frontiers in Energy Research

Received: 22 October 2015 Accepted: 30 November 2015

Published: 14 December 2015

Citation:

Robin TF, Ross AB, Lea-Langton AR and Jones JM (2015) Stability and Activity of Doped Transition Metal

Zeolites in the Hydrothermal

Processing.

Front. Energy Res. 3:51. doi: 10.3389/fenrg.2015.00051

\section{Stability and Activity of Doped Transition Metal Zeolites in the Hydrothermal Processing}

\author{
Thomas François Robin*, Andrew B. Ross, Amanda R. Lea-Langton and Jenny M. Jones \\ School of Chemical and Process Engineering, University of Leeds, Leeds, UK
}

This study investigates the stability and activity of HZSM-5 doped with metals such as molybdenum, nickel, copper, and iron under hydrothermal conditions used for the direct liquefaction of microalgae. Catalysts have been prepared by ion-exchange techniques, and MoZSM-5 was also prepared by wet incipient impregnation for comparison. Hydrothermal liquefaction is considered a potential route to convert microalgae into a sustainable fuel. One of the drawbacks of this process is that the bio-crude produced contains significant levels of nitrogen and oxygen compounds that have an impact on the physical and chemical properties of the fuel. Heterogeneous catalysts have been shown to improve the quality of the bio-crude by reducing nitrogen and oxygen contents. Zeolites, such as HZSM-5, are strong candidates due to their low cost compared to noble metal catalysts, but their stability and activity under hydrothermal conditions are not well understood. The stability of the catalysts has been determined under hydrothermal conditions at $350^{\circ} \mathrm{C}$. Catalysts have been characterized before and after treatment using X-ray diffraction, BET physisorption, and scanning transmission electronic microscopy. Metal leaching was determined by the analysis of the water phase following the hydrothermal treatment. The inserted cation following ion-exchange can influence the physical properties of HZSM-5, for example, molybdenum improves the crystallinity of the zeolite. In general, metal-doped zeolites were relatively stable in subcritical water. The activity of the catalysts for processing lipids, protein, and microalgae has been assessed. Four feedstocks were selected: sunflower oil, soya proteins, Chlorella, and Pseudochoricystis ellipsoidea. The catalysts exhibited greater activity toward converting lipids, for example, MoZSM-5 enhanced the formation of aromatic compounds. NiZSM-5 and CuZSM-5 were observed to be more efficient for deoxygenation.

Keywords: subcritical, HZSM5, transition metals, liquefaction, biomass

\section{INTRODUCTION}

Hydrothermal liquefaction has been accepted as a sustainable and efficient technique to convert biomass into bio-crude oil, for the reason that wet biomass feedstock such as microalgae can be processed without prior drying (Peterson et al., 2008). An advantage of water under hydrothermal conditions is that its chemical and physical proprieties as a solvent can be tuned in relation to its temperature and pressure. The solubility of non-polar molecules, for example, increases with temperature as the polarity of water decreases from $78 \mathrm{~F} / \mathrm{m}$ at room temperature to $14 \mathrm{~F} / \mathrm{m}$ at $350^{\circ} \mathrm{C}$ (Peterson 
et al., 2008). A disadvantage is that the bio-crude produced by the process contains a significant content of heteroatoms including oxygen (from approximately 10 to $20 \mathrm{wt}$ \%) and nitrogen (from approximately 5 to $11 \mathrm{wt} . \%$ ), which reduces the heating value of the fuel and produces $\mathrm{NO}_{\mathrm{x}}$ when combusted (Biller et al., 2011). Furthermore, heteroatoms such as oxygen can have an effect on the long-term storage and the quality of the fuel.

Heterogeneous catalysts have been used during in situ and ex situ liquefaction of microalgae in order to improve the quality of the fuels (Duan and Savage, 2010; Biller et al., 2011; Duan et al., 2013). Noble metal catalysts such as $\mathrm{Pd} / \mathrm{C}$ and $\mathrm{Pt} / \mathrm{C}$ have been selected to upgrade lipids and bio-crude from microalgae (Fu et al., 2010; Duan et al., 2013). Good rates of deoxygenation and high stability after several regeneration cycles were achieved with these catalysts. These results are encouraging, but lower-cost catalysts would improve the competitiveness of hydrothermal liquefaction compared to fossil fuel.

Zeolites such as HZSM-5 are strong candidates because of their high availability in the petrochemical industry and their acidic and microporous structures (Flanigen et al., 1991). However, a disadvantage is that this catalyst needs to be regularly regenerated because of the coke produced during the cracking of crude oils (Corma et al., 2007). Moreover, steam conditions induced a structural change with the migration of aluminum out of the catalyst framework called "dealumination." This effect is to reduce the Brønsted acidic sites and lower the catalytic activity (de Lucas et al., 1997b; Gayubo et al., 2004a,b). The "non-framework" aluminum can be reinserted into the framework by treating the dealuminated HZSM5 under harsh conditions by reflux in a solution of concentrated hydrochloric acid $(\mathrm{HCl})$ for $120 \mathrm{~h}$ at $100^{\circ} \mathrm{C}$ (Sano et al., 2000).

In order to improve the activity and stability, HZSM-5 can be doped using different transition metals. HZSM-5 was shown to be more robust under steam conditions and less coke was produced when nickel was incorporated by a wet impregnation method (from 0.5 to $3 \mathrm{wt} . \%$ loading) during the production of hydrocarbon from bio-ethanol (Gayubo et al., 2010). The ammonia temperature-programmed desorption (TPD) analysis detected that nickel enhanced the concentration of Lewis acidic sites with a reduction in Brønsted acidic sites (Gayubo et al., 2010). Molybdenum was impregnated, and due to the high acidic sites it was demonstrated to produce aromatic compounds from methane in the process called "dehydroaromatization" (Song et al., 2006, 2007). Metal-doped HZSM-5 can be prepared with other techniques such as ion-exchange. The addition of iron II to HZSM-5 allowed to convert ammonia into nitrogen and CuZSM5 which was used to convert $\mathrm{NO}_{x}$ gases (Sato et al., 1991; Long and Yang, 2000).

HZSM-5 has been demonstrated to be a more robust catalyst compared to the zeolite HY in hot compressed water (from 150 to $200^{\circ} \mathrm{C}$ ) and supercritical water at $400^{\circ} \mathrm{C}$ (Ravenelle et al., 2010; Mo and Savage, 2014). A mild change in the structure detected by the X-ray diffraction (XRD) analysis of the silica bonding was observed at $400^{\circ} \mathrm{C}$. In addition, HZSM-5 appeared to be more robust after several regeneration cycles by oxidation of the catalyst with a consistent activity to produce hydrocarbons from palmitic acid. More recently, a more acidic zeolite with a low ratio of $\mathrm{Si} / \mathrm{Al}$ (or the $\mathrm{SiO}_{2} / \mathrm{Al}_{2} \mathrm{O}_{3}$ ratio) was more selective to produce aromatic compounds in supercritical water, nevertheless, a higher $\mathrm{Si} / \mathrm{Al}$ ratio zeolite was more stable under the same condition (Mo et al., 2015). For the reason that the propriety of the water are different at $350^{\circ} \mathrm{C}$ compared to $400^{\circ} \mathrm{C}$, it would be interesting in study the stability of HZSM-5 at $350^{\circ} \mathrm{C}$.

Zeolites including HZSM-5 and HY have already been used to process biomass, bio-crude oil, and fatty acids in hydrothermal liquefaction (Duan and Savage, 2010; Yang et al., 2011; Bai et al., 2014; Mo and Savage, 2014). HZSM-5 has been demonstrated to be a good catalyst to produce paraffinic oil with a high carbon content from the upgrading of a microalgal pretreated crude oil (Mo and Savage, 2014). Overall, HZSM-5 was more selective compared to other zeolites such as $\mathrm{H} \beta$ and HY to produce aromatic compounds from fatty acids at higher temperatures (Mo et al., 2015). Pretreating a bio-crude oil with the same catalyst reduced the nitrogen content, although the production of coke (28 wt.\%) was more significant above $400^{\circ} \mathrm{C}$ compared to the other catalysts which represents a drawback (Bai et al., 2014).

The aim of this study is to investigate whether HZSM-5 catalysts retain the same chemical properties and stability under subcritical hydrothermal conditions. This study characterizes the metal-doped zeolites with molybdenum, nickel, copper, and iron cations produced using the ion-exchange method. Subsequently, their stabilities are investigated in subcritical water $\left(350^{\circ} \mathrm{C}\right)$. The changes of physical or chemical properties are observed using techniques such as X-ray crystallography, surface area (BET), and scanning transmission electronic microscopy (STEM). Moreover, two methods (ion-exchange and wet incipient wetness) were investigated to prepare MoZSM-5; molybdenum was selected because of previous results from the literatures with good activities and to investigate the impact on the stability and the activity from different methods of preparation (Song et al., 2006, 2007). The activity of HZSM-5, MoZSM-5, CuZSM-5, FeZSM-5, and NiZSM-5 was investigated with soya proteins and two microalgae with different compositions: Pseudochoricystis ellipsoidea and Chlorella. The bio-crude composition was analyzed by elemental analysis, gas chromatography-mass spectrometry (GC-MS), and gel permeation chromatography (GPC). Finally, the deoxygenation and denitrogenation of the processed bio-crude oil, using the catalysts prepared by ion-exchange, were investigated.

\section{MATERIALS AND METHODS}

\section{Materials}

The microalga strain P. ellipsoidea was supplied by Denso Corporation and has been used in other work (Biller et al., 2013). Sunflower oil, Chlorella vulgaris and soy protein were obtained from commercial sources. $\mathrm{NH}_{4}-\mathrm{ZSM}-5$ was supplied by Alfa Aesar, the metal salts were supplied by Sigma Aldrich.

\section{Preparation and Characterization of Metal-Doped HZSM-5}

The zeolite in the form of $\mathrm{NH}_{4}-\mathrm{ZSM} 5$ was calcined for $3 \mathrm{~h}$ at $550^{\circ} \mathrm{C}$ under a constant flow of air $(50 \mathrm{ml} / \mathrm{min})$ to yield HZSM5. The Si/ $\mathrm{Al}$ ratio was 27 (4.9 wt.\%, for the aluminum while silica $82.2 \mathrm{wt} . \%$ 
of silica) where the silica content was determined by colorimetry and the aluminum content by atomic absorption spectroscopy (AAS). According to the method by Long and Yang (2000), the metal ion-exchanged catalysts were prepared as follows: $20 \mathrm{~g}$ of $\mathrm{NH}_{4}$-ZSM5 was mixed with a $0.05 \mathrm{M}$ solution of metal salts [copper acetate $\mathrm{Cu}(\mathrm{acac})_{2}$, iron nitrate $\mathrm{Fe}\left(\mathrm{NO}_{3}\right)_{3}$, nickel acetate, ammonium molybdate] under constant stirring for $24 \mathrm{~h}$. The solid was washed and filtered under Buchner, then dried at $110^{\circ} \mathrm{C}$ overnight. Finally, the doped zeolite was calcined at $550^{\circ} \mathrm{C}$ for $5 \mathrm{~h}$. The chemical composition of metal ion-exchanged zeolites were analyzed by AAS (with an average coefficient of variance of $3.7 \%$ ) after acid digestion and were determined as containing the following metal loadings: FeZSM5 0.3 wt.\%, MoZSM5 0.1 wt.\%, CuZSM-5 1.2 wt.\%, and NiZSM-5 0.1 wt.\%. Two batches of NiZSM- 5 were produced, where the metal loading had a coefficient of variance of $10.3 \%$.

For the preparation of the impregnated sample of molybdenum (5 wt.\%), $0.9 \mathrm{~g}$ of ammonium molybdate tetrahydrate $\left[\left(\mathrm{NH}_{4}\right)_{6} \mathrm{Mo}_{7} \mathrm{O}_{24} 4 \mathrm{H}_{2} \mathrm{O}\right]$ was dissolved into $1.5 \mathrm{ml}$ of water (pore of the HZSM-5 is $0.15 \mathrm{ml} / \mathrm{g}$ ) and poured in $10 \mathrm{~g}$ of HZSM-5. The slurry was crushed, mixed well, and finally dried overnight (more than $12 \mathrm{~h}$ ) at $105^{\circ} \mathrm{C}$. The final step was the calcination of the solid at $550^{\circ} \mathrm{C}$ for $4 \mathrm{~h}$ under a constant flow of air at $50 \mathrm{ml} /$ min. For the impregnated molybdenum sample, $4.5 \mathrm{wt} . \%$ of metal was measured by AAS.

The preparation of the kaolin-HZSM-5 pellet was carried out as follows: $2.1 \mathrm{~g}$ of kaolin clay and $1.0 \mathrm{~g}$ binder polyvinyl alcohol (PVA) with a molecular weight of $88,000 \mathrm{~g} / \mathrm{mol}$ were mixed in $20 \mathrm{ml}$ of water for $30 \mathrm{~min}$. Subsequently, $22 \mathrm{ml}$ of concentrated $\mathrm{HCl}$ (35 vol.\%) was carefully added drop-wise for $1 \mathrm{~h}$ by stirring, forming a foam. Subsequently, a suspension of $2 \mathrm{~g}$ of HZSM-5 in $20 \mathrm{ml}$ of water was added into the slurry under constant mixing for $30 \mathrm{~min}$. The water was evaporated on a hot plate for $6 \mathrm{~h}$, and the residue was further dried in an oven overnight. The solid was calcined at $550^{\circ} \mathrm{C}$ for $1 \mathrm{~h}$, once it had cooled down. The solid was washed with $45 \mathrm{ml}$ of water and $0.094 \mathrm{~g}$ of ammonium chloride $\left(\mathrm{NH}_{4} \mathrm{Cl}\right)$ to remove any trace of sodium. The mixture was stirred under a mild heating at $60^{\circ} \mathrm{C}$ for $30 \mathrm{~min}$. The residue was retrieved by filtration and subsequently calcined at $550^{\circ} \mathrm{C}$ for $3 \mathrm{~h}$.

The XRD measurements were performed using a BRUKERbinary V3 machine and used to determine the crystallinity and phases present in the fresh and the processed sample; HZSM-5 was mixed with a standard solution of alumina corundum as a reference for quantification with a ratio of 3:1. Indeed, intensity depends on different parameters such as the moisture and the presence of amorphous material; with the mixture, this parameter is reduced. The sum of the intensity between $20^{\circ}$ and $25^{\circ}$ is chosen as this peak is influenced by the $\mathrm{Si} / \mathrm{Al}$ (Pollack et al., 1984) and $35^{\circ}$ and $40^{\circ}$ for the alumina. Crystallinity is estimated using Eq. 1, where the ratio of the fresh sample with the used one was taken, $I$ is the increment of the measurement.

$$
\% \text { Crystallinity }=\frac{\frac{\sum \text { intenstity fresh }[20-25] \times I_{\mathrm{a}}}{\sum \text { intensity fresh }[35-40]}}{\frac{\sum \text { intensity HTL }[20-25] \times I_{\mathrm{b}}}{\sum \text { intensity HTL }[35-40]}}
$$

The BET surface area and the pore size [Barrett, Joyner, and Halenda (BJH) method] were determined using a Quantachrome $2200 \mathrm{e}$ model. Approximately, $0.1 \mathrm{~g}$ of sample was degassed under vacuum at $300^{\circ} \mathrm{C}$. The adsorption-desorption was carried out at $77 \mathrm{~K}\left(-196^{\circ} \mathrm{C}\right)$ using 42 points. The surface area of the calcined ZSM5 support was found to be $388 \mathrm{~m}^{2} / \mathrm{g}$.

Scanning transmission electronic microscope is conducted using an FEI Tecnai F20 field emission gun (FEG)-TEM operated at $200 \mathrm{kV}$ and equipped with a Gatan Orius SC600A CCD camera and an Oxford Instruments 80-mm X-Max SDD detector. STEM samples were prepared by dispersing powders in isopropanol, with a drop placed on a holey carbon-coated copper grid (Agar Scientific).

\section{Hydrothermal Processing}

The hydrothermal processing of different biomasses was performed in an unstirred batch reactor (77 $\mathrm{ml}$, Parr, USA). The processing of biomass was carried out as follows: $3 \mathrm{~g}$ of biomass (sunflower oil, soy proteins, C. vulgaris, P. ellipsoidea), $0.5 \mathrm{~g}$ of catalyst, and $27 \mathrm{ml}$ of deionized water were introduced into the reactor, which were subsequently pressurized with 2 bar nitrogen. Most of the experiments were carried out in duplicate with an average coefficient of variance of $6.5 \%$. The reactor was heated with a heating rate of approximately $9^{\circ} \mathrm{C} / \mathrm{min}$. The reactor was held at the final temperature of $350^{\circ} \mathrm{C}$ for $1 \mathrm{~h}$. Pressures achieved were recorded approximately from 140 to 160 bars.

For the regeneration experiments, pellet HZSM-5 was recycled four times in the presence of sunflower oil as follows: $3 \mathrm{~g}$ of sunflower oil, $0.5 \mathrm{~g}$ of HZSM-5, and $27 \mathrm{ml}$ of water were added into the reactor and heated to $350^{\circ} \mathrm{C}$ for $1 \mathrm{~h}$. Pellets were prepared by using a press and bringing a pressure of $1 \mathrm{t}$ using HZSM5 of a size of 100-80 mesh. The first experiment was performed six times, for the second cycle, three experiments were carried out, subsequently two and for the last cycle only one. At the end, the catalyst was washed with water and dichloromethane (DCM), and finally it was dried and recycled for the next cycle.

\section{Sample Workup and Analysis}

Once the reactor was cooled and opened, it was first rinsed with $50 \mathrm{ml}$ of deionized water and subsequently by $50 \mathrm{ml}$ of DCM. The two phases were mixed together in a separating funnel and allowed to separate. The organic phase (DCM) was separated and filtered using a 1-PS filter and left to evaporate at room temperature for approximately 2 days to obtain the mass yield of crude oil. The aqueous phase was filtered under vacuum using a Buchner filter (filter grade 5) in order to collect the residue and the catalyst. Finally, the aqueous phase was diluted to $1 \mathrm{l}$. Yields, including the bio-crude and residue (Datasheet S1 in Supplementary Material), were calculated according to the mass of the oil and residue collected as dry weight; the gaseous yield (Datasheet S1 in Supplementary Material) was calculated according to the previous studies (Biller and Ross, 2011; Biller et al., 2011). The residue phase was measured by the weight of the residue collected on filters of the organic and aqueous phases minus the weight of the catalyst. The aqueous phase yield was calculated by the difference of the other phases (bio-crude, gaseous, and residue). Figure 1 describes the general procedure of the workup. 


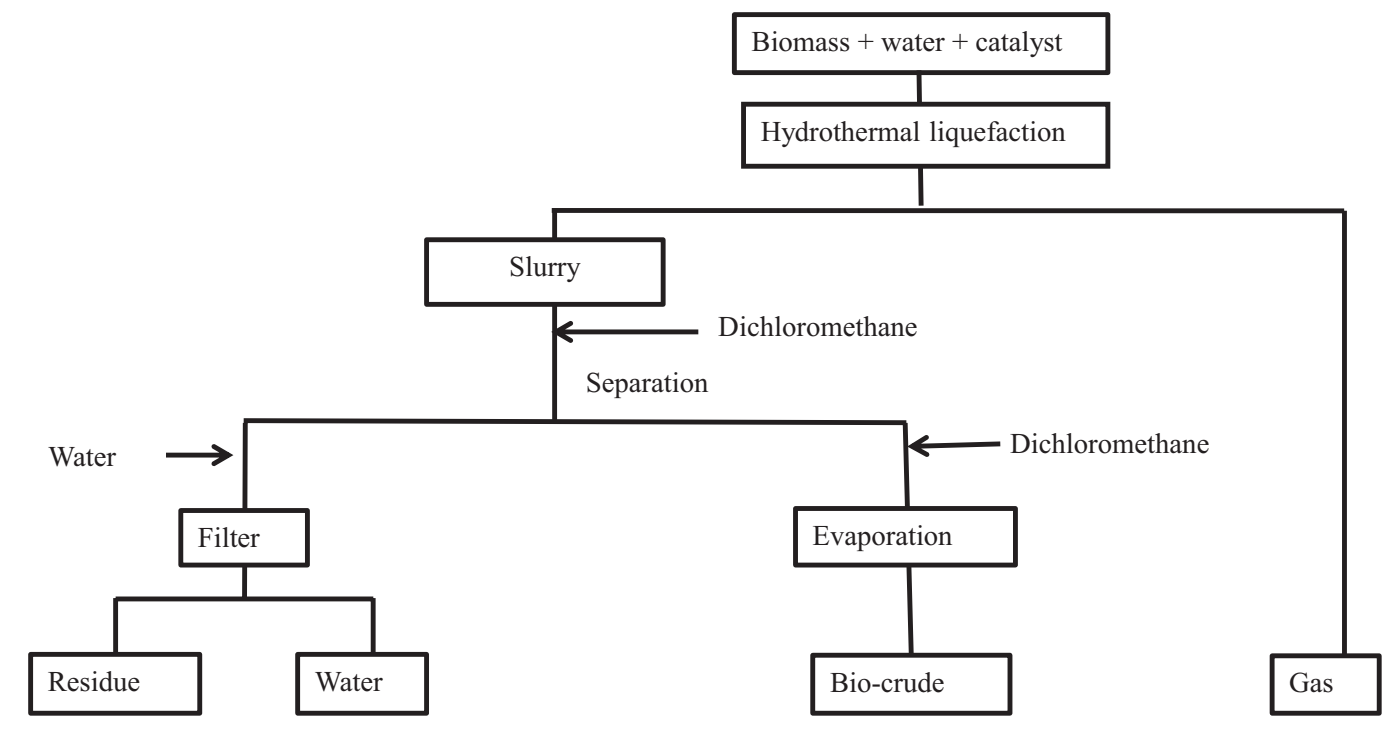

FIGURE 1 | Schematic of the experimental procedure for hydrothermal liquefaction of biomass.

Following evaporation, a fraction of the bio-crude oil was redissolved in DCM to obtain a concentration of approximately 10 wt.\% and analyzed by GC-MS using an Agilent 5975B inert MSD. Separation of the products was achieved using an RTx 1701 60 -m capillary column, $0.25 \mathrm{id}, 0.25 \mu \mathrm{m}$ film thickness using the following temperature program: $40^{\circ} \mathrm{C}$, hold time $2 \mathrm{~min}$, ramped to $280^{\circ} \mathrm{C}$ at $60^{\circ} \mathrm{C} / \mathrm{min}$, hold time $10 \mathrm{~min}$ with a split ratio of $1: 10$. The column head pressure was 30 psi at $40^{\circ} \mathrm{C}$.

Gel permeation chromatography was performed using a Perkin Elmer Series 200 HPLC instrument fitted with a refractive index detector. The column used was a Varian PGel $30 \mathrm{~cm}$ length with a diameter of $7.5 \mathrm{~mm}$ and a particle size of $100 \AA$, the flow rate of mobile phase was $1 \mathrm{ml} / \mathrm{min}$ in stabilized tetrahydrofuran (THF). The sample was measured in a $1.5-\mathrm{ml}$ vial, a concentration of $10 \mathrm{wt} . \%$ using THF as solvent. The instrument was calibrated using different molecular weight polystyrene polymer standards (poly laboratories). The percent fraction of different weight was determined by the integration of curve by the software Origin 8 at different molecular size ranges: the first fraction was integrated between 8.5 and $11 \mathrm{~min}(0-200 \mathrm{~g} / \mathrm{mol})$, the second fraction from 8 to $8.5 \mathrm{~min}(200-600 \mathrm{~g} / \mathrm{mol})$, third fraction from 7.5 to $8 \mathrm{~min}(600-1000 \mathrm{~g} / \mathrm{mol})$, and the last fraction from 6 to $7.5 \mathrm{~min}$ (superior to $1000 \mathrm{~g} / \mathrm{mol}$ ). The ash content of the raw material $(1.0 \mathrm{~g})$ was measured in crucible with a muffle furnace for $3 \mathrm{~h}$ at $550^{\circ} \mathrm{C}$.

For the elemental analysis (CHNS) of the bio-crude oil, the oil was filtered using a 1-PS grade filter to remove any residue or moisture. Subsequently, the oils were dissolved in a DCM/ methanol (10 vol.\%) solution with a ratio of oil/solvent, 1:4, and placed into smooth wall tin capsules. Solvents were evaporated before the analysis using CE instruments Flash EA 1112 series elemental analyzer. The high heating value (HHV) with a unit of megajoule per kilogram was calculated using the Dulong formula, as shown in Eq. 2 (Corbitt, 1999); C, H, O, and S represent the weight percentage of the carbon, hydrogen, oxygen, and sulfur, respectively, measured by the elemental analysis. The energy recovery was calculated using Eq. 3 , where $m_{\text {bio-crude }}$ and $m_{\text {raw sample }}$ are the masses in grams as dry basis; HHV were calculated using the previous equation.

$$
\begin{gathered}
\mathrm{HHV}=0.338 \times \mathrm{C}+1.428 \times\left(\mathrm{H}-\frac{\mathrm{O}}{8}\right)+0.095 \times \mathrm{S} \\
\% \text { Energy recovery }=\frac{\mathrm{HHV}_{\text {bio-crude }} \times m_{\text {bio-crude }}}{\mathrm{HHV}_{\text {raw sample }} \times m_{\text {raw sample }}} \times 100
\end{gathered}
$$

The determination of coking during the recycling step was carried out using the Netzsch STA (simultaneous thermal analyzers) from a previous study (Ortega et al., 1997). During the first step, impurities were removed by pyrolyzing approximately $20 \mathrm{mg}$ of samples in a constant flow of helium at $100 \mathrm{ml} / \mathrm{min}$ with a heating rate of $10^{\circ} \mathrm{C} / \mathrm{min}$ and holding at $500^{\circ} \mathrm{C}$ for $30 \mathrm{~min}$. This following program was used to stabilize the coke. In the second step, combustion was performed; the amount of coke was measured from 300 to $550^{\circ} \mathrm{C}$ with a heating rate of $10^{\circ} \mathrm{C} / \mathrm{min}$ in a gaseous mixture of $12.5 \mathrm{vol} . \% \mathrm{O}_{2} / \mathrm{He}$, and this temperature is held for $30 \mathrm{~min}$. Combustion gases were determined using an online FT-IR. The wavelength of carbon dioxide $\left(\mathrm{CO}_{2}\right)$ measured is $2362 \mathrm{~cm}^{-1}$ and for carbon monoxide (CO) $2175 \mathrm{~cm}^{-1}$, and water $\left(\mathrm{H}_{2} \mathrm{O}\right) 3400 \mathrm{~cm}^{-1}$. The STA was calibrated by melting pure metals. At least five points are used to create these calibration curves. Each point corresponds to data obtained from the melting of a different metal. The metals were selected to more or less cover the range of temperatures for the measurements [i.e., from In (indium) $\left(156.6^{\circ} \mathrm{C}\right)$ to $\mathrm{Au}($ gold $\left.)\left(1064.4^{\circ} \mathrm{C}\right)\right]$. In addition, a buoyancy (aka background, correction, and calibration) correction is also done under the same conditions as the experiments (i.e., gases, flow rates, heating rates, and duration of isothermal steps). 
Equation 4 is used to calculate the $\mathrm{H} / \mathrm{C}$ ratio of the coke. $n_{\mathrm{H}_{2} \mathrm{O}}$ represents the molar amount of water calculated from the infrared spectrum; $n_{\mathrm{CO}}$ and $n_{\mathrm{CO}_{2}}$ are also determined from the absorbance of $\mathrm{CO}$ and $\mathrm{CO}_{2} . \% \mathrm{C}$ represents the total carbon content for both gases. The spectrometer was previously calibrated with calcium oxalate using the following program, in helium gas with a heating rate of $10^{\circ} \mathrm{C} / \mathrm{min}$ to $900^{\circ} \mathrm{C}$.

$$
\frac{\mathrm{H}}{\mathrm{C}}=\frac{\frac{\% \mathrm{H} \text { in water } \times n_{\mathrm{H}_{2} \mathrm{O}}}{2}}{\frac{\left(n_{\mathrm{CO}}+n_{\mathrm{CO}_{2}}\right) \times \% \mathrm{C}}{12}}
$$

The concentration of $\mathrm{CO}_{2}, \mathrm{CO}$, and water are calculated in order to know the $\mathrm{H} / \mathrm{C}$ of the coke. The equation is deduced from the calibration of the water in Eq. 5 where $x$ is the mass of water and $y$ is the absorbance. The equation for $\mathrm{CO}$ is in Eq. 6 and $\mathrm{CO}_{2}$ is in Eq. 7.

$$
\begin{aligned}
& y=0.6363 x+0.2291 \\
& y=0.2147 x+0.2703 \\
& y=3.4127 x+4.4405
\end{aligned}
$$

\section{RESULTS}

\section{The Stability of HZSM5 Under Subcritical Condition \\ Characterization of the Catalyst}

The first section presents the experimental results regarding the initial composition and the hydrothermal stability of metaldoped catalysts at $350^{\circ} \mathrm{C}$.

The method of ion-exchange is the most efficient with copper with $1.2 \mathrm{wt} . \%$. The metal loading found for the ion-exchanged metal are lower compared to the literature obtained by the same conditions with 1.6, 0.8 , and $4.3 \mathrm{wt}$.\% for iron, nickel, and copper, respectively (Long and Yang, 2000).

The metal loading was more significant with molybdenum using the wet incipient impregnation method compared to the ion-exchange. The loading of metal probably depends on the size of the element to enter through the pore. Figure 2 shows two examples of STEM results for two catalysts Figure 2A FeZSM-5 and Figure 2B MoZSM-5, where (i) is the STEM images, (ii) EDX, and (iii) HAADF imaging (high-angle annular dark field), where the bright spot represents heavy molecular weight metals. The square corresponds to the place, where the EDX measurement was carried out. The copper found in the EDX scan was from the grid. However, it was difficult to obtain clear pictures with this material, because it began to degrade under the electron beam after a few minutes hence then the structure starts to deteriorate.

The image suggests that iron formed clusters at the edge of the particle with a size of approximately $16 \mathrm{~nm}$, the presence of iron is confirmed by EDX although this technique does not allow the quantification of metals. Figure 2B proposes that molybdenum is located inside the pores as observed with the image (iii) forming a bright spot of approximately $1 \mathrm{~nm}$. Nickel (STEM not shown) probably forms a thin layer as the EDX identifies nickel without seeing any difference, implying that no brighter spot was observed by HAADF technique. A lattice network with a size of $1.6 \mathrm{~nm}$ for the unprocessed HZSM-5 was measured from the STEM images in Figure S1 in Supplementary Material.

\section{Stability}

The method of subcritical water liquefaction involves harsh conditions with high pressure between 140 and 150 bar at $350^{\circ} \mathrm{C}$. Therefore, catalysts should be robust under these circumstances. Metal leachates from the reactor are measured by ICP-OES, a blank experiment is carried out and the main cations detected are iron, calcium, and nickel with a concentration of 1.1, 1.0, and $2.7 \mathrm{mg} / \mathrm{l}$, respectively.

Generally, the dealumination is low with approximately 0.2 wt.\% leaching of the HZSM-5. As said earlier, the migration of aluminum was possible out of the framework (de Lucas et al., 1997b). The loss of silica is more significant with approximately 20.0 wt.\%. This result is in accordance with the previous study (Ravenelle et al., 2010), where the hydrolysis of the siloxane bond ( $\mathrm{Si}-\mathrm{O}-\mathrm{Si})$ was enhanced in hot compressed water $\left(150-200^{\circ} \mathrm{C}\right)$; these phenomena do have an impact on the reactivity for HZSM-5 as discussed in the following section. The leaching of the doped metal at $350^{\circ} \mathrm{C}$ is high with $6.2 \mathrm{wt} . \%$ for FeZSM-5, $7.9 \mathrm{wt} . \%$ for CuZSM-5, 10.0 wt.\% with NiZSM-5, and 34.0 wt.\% with MoZSM5. These results are counterintuitive with the STEM analysis as described in the previous section, as iron is located outside the particle which is more subject to sintering, while molybdenum is found in the pores. Yet, these leachate ions could have a catalytic impact during the liquefaction of biomass. For MoZSM- 5 between the impregnated and ion-exchanged samples, a similar value is measured (35.0 wt.\%). Molybdenum might have reacted with the silica leachate as the aqueous phase is blue after the stability test.

The loss of aluminum and silica is lower than the doped metal, especially with FeZSM-5 and MoZSM-5 with 11.2 and 7.2 wt.\% of leachate of silicon. Thus, these metals could have an impact on the strength of the silica framework. The STEM imaging of the samples treated in subcritical water at $350^{\circ} \mathrm{C}$ suggests that the lattice interstice widens to $2.3 \mathrm{~nm}$. For the processed MoZSM-5, the EDX shows no indication of the presence of molybdenum, but the sample is degraded under the beam for a long time and it is difficult to be certain. An agglomeration of iron (shown in Figure S2 in Supplementary Material) is observed in some concentrated part, whereas elsewhere no iron has been detected. Some traces of nickel (shown in Figure S3 in Supplementary Material) are detected in the processed sample, although the size is too small to be seen by STEM HAADF, the EDX show traces of nickel.

\section{The Effect of the Surface Area and Pore Sizes}

The pore size of HZSM-5 is located in the majority of the microporous region below $1.8 \AA$ (radius) calculated by the HorvathKawazoe (HK) method. Table 1 compares the surface area $\left(\mathrm{m}^{2} / \mathrm{g}\right)$ and the cumulative pore volume $(\mathrm{ml} / \mathrm{g})$ of the fresh and the used metal-doped HZSM-5. The BJH method allowed the calculation of the cumulative volume in the micro- and mesoporous. This method predicts the pressure when condensation happens inside the cylindrical pore. 

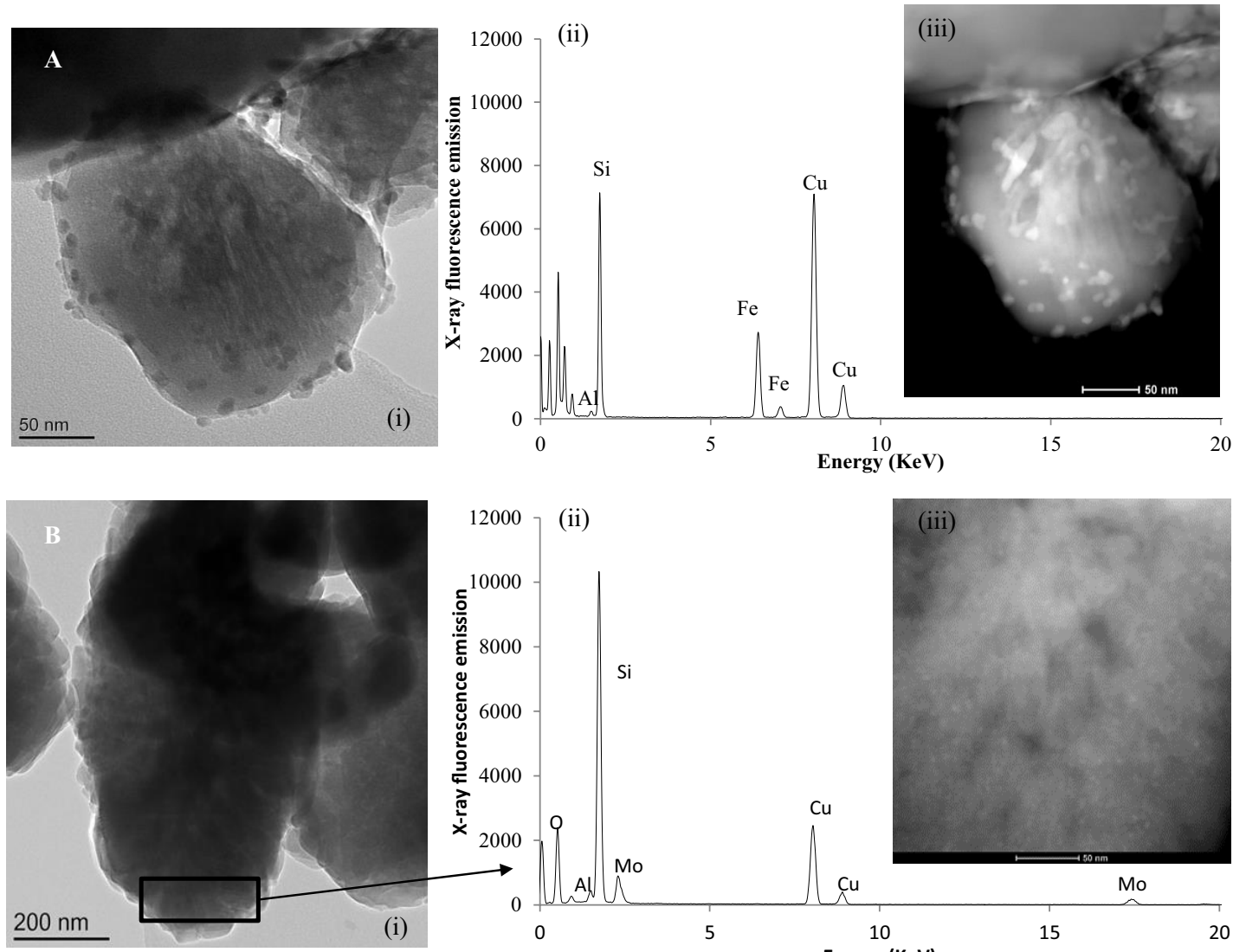

(ii)

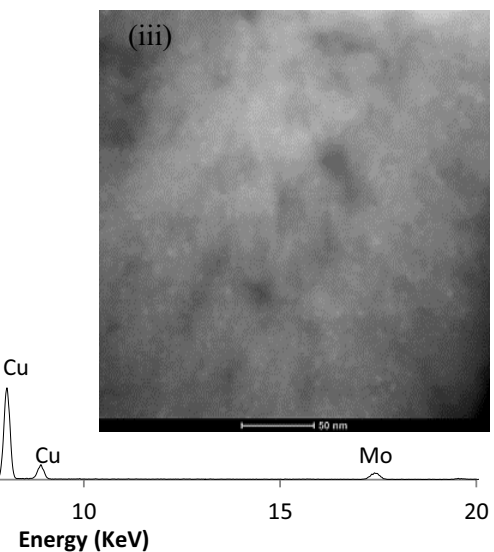

FIGURE 2 | STEM of different metal-doped HZSM-5, where (A) is FeZSM-5 and (B) is MoZSM-5; (i) STEM analysis; (ii) EDX (iii) analysis of the HAADF (high-angle annular dark field).

TABLE 1 | BET values calculated for fresh and used doped HZSM-5; pore volume and desorption calculated by the BJH methods.

\begin{tabular}{lcccc}
\hline Catalysts & $\begin{array}{c}\text { Surface } \\
\text { area }\left(\mathbf{m}^{2} / \mathbf{g}\right)\end{array}$ & $\begin{array}{c}\text { Cumulative } \\
\text { pore volume } \\
(\mathbf{m l} / \mathbf{g})\end{array}$ & $\begin{array}{c}\text { Surface } \\
\text { area after } \\
\text { hydrothermal } \\
\text { run }\left(\mathbf{m}^{2} / \mathbf{g}\right)\end{array}$ & $\begin{array}{c}\text { Cumulative } \\
\text { hydrothermal } \\
\text { pore volume } \\
\mathbf{( m l} / \mathbf{g})\end{array}$ \\
\hline HZSM-5 & 382 & 0.09 & 141 & 0.05 \\
CuZSM-5 & 384 & 0.09 & 285 & 0.05 \\
FeZSM-5 & 399 & 0.09 & 52 & 0.03 \\
MoZSM-5 & 435 & 0.1 & 250 & 0.07 \\
ion-exchanged & & & & \\
NiZSM-5 & 370 & 0.1 & 219 & 0.1 \\
MoZSM-5 & 321 & 0.1 & 184 & 0.1 \\
impregnated & & & & \\
Kaolin-pellet & 174 & 0.09 & 200 & 0.4 \\
HZSM-5 & & & &
\end{tabular}

During the hydrothermal treatment using HZSM-5, the average pore size remains unchanged, that is, $1.8 \AA$. The volume of the mesoporous, measured by the $\mathrm{BJH}$ method, is $0.05 \mathrm{ml} / \mathrm{g}$. The difference between the fresh and doped samples is probably caused by the metal blocking the pores. Copper increases the cumulative pore volume compared to HZSM-5. Impregnated HZSM-5 with molybdenum has a lower surface area than HZSM- 5 doped by ion-exchange. In the literature, a surface area of $324 \mathrm{~m}^{2} / \mathrm{g}$ for the plain HZSM-5 was measured which was lower than the value during this study (Idem et al., 1997). A surface area of $334 \mathrm{~m}^{2} / \mathrm{g}$ and a pore volume of $0.11 \mathrm{ml} / \mathrm{g}$ were determined for impregnating HZSM-5 with nickel (0.5 wt.\%) (Gayubo et al., 2010). The surface area of the pellet was lower compared to the pure material as the binder (the clay kaolin) had a very low surface area of approximately $15 \mathrm{~m}^{2} / \mathrm{g}$.

Under subcritical condition, abrasion of the catalyst was observed with the loss of surface area. Indeed, a 25\% of loss was calculated between the fresh and the used sample at $350^{\circ} \mathrm{C}$. The reduction was more significant with FeZSM-5 with $87 \%$ of loss (between the two values). Under steam, iron enhanced the migration of aluminum from the framework and reduced the dispersion of the metal; the same phenomena might result in the loss of surface area (Pieterse et al., 2007). The observation in the STEM, described in the previous section, confirmed that iron formed cluster during this condition. In the literature, no change in pore volume was noticeable in the microporous and mesoporous in hot compressed water $\left(150-200^{\circ} \mathrm{C}\right)$ and in supercritical water as well (Ravenelle et al., 2010; Mo et al., 2015). 
TABLE 2 | Peak area ratio of mixture $25 \% \mathrm{HZSM}-5-75 \% \gamma \mathrm{Al}_{2} \mathrm{O}_{3}$ for the determination of the percentage of crystallinity.

\begin{tabular}{|c|c|c|c|c|c|c|}
\hline & HZSM-5 & FeZSM-5 & $\begin{array}{l}\text { MoZSM-5 } \\
\text { exchanged }\end{array}$ & CuZSM-5 & NiZSM-5 & $\begin{array}{c}\text { MoZSM-5 } \\
\text { impregnated }\end{array}$ \\
\hline$\%$ Crystallinity compared to the fresh catalyst & 75.5 & 77.4 & 86.2 & 72.4 & 79.2 & 75.6 \\
\hline
\end{tabular}

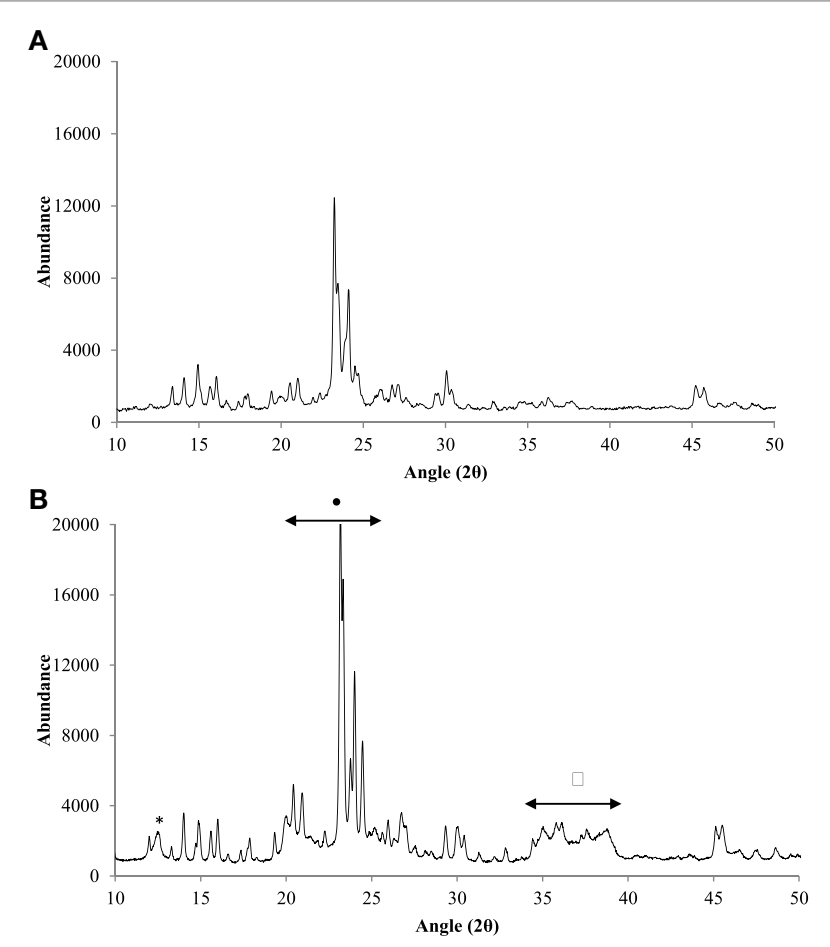

FIGURE 3 | Overlay of the fresh (A) and used (B) pellet 40-40 kaolin-HZSM-5.

For the majority of samples, with the exception of the kaolin-pellet HZSM-5, a decrease in cumulative pore volume (mesoporous) is apparent probably caused by the destruction of pores during the elevated pressure. Nevertheless, the $\mathrm{BJH}$ desorption profile indicates that new pores have been created in the region of 20-30 $\AA$ for HZSM-5 and CuZSM-5, from 80 to $110 \AA$ for FeZSM-5 and in the region of $120 \AA$ for MoZSM-5. Interestingly, the surface area of the kaolin-pellet increases the surface area to $200 \mathrm{~m}^{2} / \mathrm{g}$, which implies that the binder and the clay enhance the stability toward abrasion. Moreover, the pore volume is larger than the fresh catalyst. To conclude, subcritical water has an impact on the physical aspect of HZSM-5, yet binder could enhance the stability of the catalyst.

\section{Crystallinity of HZSM-5}

HZSM-5 has high crystallinity and the metal loading was too small to observe a peak on the XRD spectrum. Table 2 lists the crystallinity value calculated using Eq. 1 .

Doped metal with the exception of CuZSM-5 enhanced the percentage of the crystallinity after the stability test compared to the plain HZSM-5. Yet, molybdenum prepared by ion-exchange had the highest effect compared to the other samples. Generally,
TABLE 3 | Yield (wt.\%) of the hydrothermal processing of sunflower oil at $350^{\circ} \mathrm{C}$ for $1 \mathrm{~h}$ in a $77 \mathrm{ml}$ bomb reactor recycling HZSM5 four times.

\begin{tabular}{lcc}
\hline Experiment & $\begin{array}{c}\text { Bio-crude } \\
\text { yield (wt.\%) }\end{array}$ & $\begin{array}{c}\text { Coke formed } \\
\text { (wt.\%) }\end{array}$ \\
\hline HTL of sunflower with pellet HZSM5 cycle 1 & 82.4 & 2.6 \\
HTL of sunflower with pellet HZSM5 cycle 2 & 92.0 & 3.9 \\
HTL of sunflower with pellet HZSM5 cycle 3 & 84.5 & 4.2 \\
HTL of sunflower with pellet HZSM5 cycle 4 & 91.5 & 3.4 \\
\hline
\end{tabular}

impregnated samples have a lower crystallinity with 75.6 for molybdenum compared to ion-exchange metal-doped HZSM-5. Even though FeZSM-5 has a low surface area, its crystallinity is higher than HZSM-5. Copper contains slightly more amorphous material than HZSM-5.

Figure 3 represents the X-ray spectrum overlay between the fresh and the samples treated in subcritical water for the kaolinpellet HZSM-5. The main difference with the used sample is the presence of new peak at approximately $12^{\circ}$ (marking with ${ }^{*}$ ) and the intensity is larger between two regions of $21-25^{\circ}(\bullet)$ and $35-40^{\circ}(\square)$. The change in intensity could be caused by the presence of moisture and amorphous material (explaining why previously zeolite was mixed with a reference material). This pellet is mixed with kaolin clay that was an amorphous material.

Two new peaks appeared after two regeneration tests in supercritical water with no effect, though on the activity as these peaks disappeared after calcination (Mo and Savage, 2014). No change of structure was noticed under low temperature (Ravenelle et al., 2010).

To summarize, these metals have an impact on enhancing the crystallinity or for some the surface area. Impregnated doped metals with a high loading do not have an effect on the physical property of HZSM-5. The next step was to test this catalyst with real biomass.

\section{Regeneration of HZSM-5}

The regeneration and the stability of pellet HZSM-5 (compressed pellet) are investigated in this section. Regeneration experiment has already been carried out (Mo et al., 2015) in supercritical water; however, in this study, a different insight brings to the analysis of the composition of the coke. Table 3 includes the bio-crude yield measured after the HTL reaction with a coefficient of variance of $4.6 \%$ and the weight percent of coke which are calculated from the thermogravimetric curve and weight loss (from 300 to $900^{\circ} \mathrm{C}$ ). During this process, according to the details in the study (Ortega et al., 1997), the first stage heated the catalyst to $500^{\circ} \mathrm{C}$ under high flow of helium to age the coke and subsequently the coke was combusted from 300 to $900^{\circ} \mathrm{C}$.

The initial size of the pellet was approximately $1 \mathrm{~mm}$ of diameter, yet after each experiment, the size of the particles was 
reduced due to the abrasion; this is the reason that cycle 1 is carried out six times, in order to have sufficient catalyst $(0.5 \mathrm{~g})$ for the last cycle. The bio-crude yield increases from step 1 to 2 and subsequently the bio-crude yield is leveled out with cycle 3 (regarding the error margin) and cycle 4 . The yield of the gaseous yield is $4.2 \mathrm{wt} . \%$ for the cycle 1 and for the next cycles (from cycle 2 to 4 ) it is approximately $3.8 \mathrm{wt} . \%$. Yet, the yield is higher than the powder HZSM-5 with 68.0 wt.\% (experiment, as discussed in the next section) indicating that the cracking is less efficient with compressed pellet as the surface area of contact was higher than the powder. In other words, lipids could not access the acidic site. The coke content increases throughout cycles 1-3 and decreases for the last regeneration 4 . Between each stage, the catalyst is dried, but not calcined. Compared to the pyrolysis, the formation of coke is up to $6 \mathrm{wt} . \%$, whereas under subcritical condition the coking was lower (de Lucas et al., 1997a). The gas emission is analyzed by the FT-IR, where the absorption of the $\mathrm{CO}, \mathrm{CO}_{2}$, and water are detected during the combustion stage. Thanks to a calibration, the mass is calculated and presented in Table 4.

The $\mathrm{H} / \mathrm{C}$ ratio of the coke decreased after the second cycle. The previous study proposed that the reduction in the $\mathrm{H} / \mathrm{C}$ ratio was caused by the dealumination and the increase in the formation of coke. Moreover, a low $\mathrm{H} / \mathrm{C}$ ratio indicates the presence of aromatic compounds in the coke (de Lucas et al., 1997a). Thus, HZSM-5 started to degrade after the third cycle. During the first step with pyrolysis, a large amount of methane is produced implying that even with the washing with DCM, some aliphatic compounds are trapped inside the structure of HZSM-5. Subsequently, during the combustion stage mainly $\mathrm{CO}$ and $\mathrm{CO}_{2}$ are formed.

A reduction in the surface area is caused by the abrasion of the pellet, and the saturation of the pores by coke is observed. The surface area levels out between the cycles 3 and 4 . The same observation was drawn previously with a reduction in surface area and the loss of cumulative total pore volume (Mo et al., 2015).

Despite some physical change during the regeneration experiment, no major change is observed in the bio-crude yield. Thus, HZSM-5 is stable during the recycling process. The stability of the pellet (kaolin-HZSM-5) should be investigated as it showed good resistance to abrasion and also the ion-exchanged catalysts. Even though, impregnated metal-doped catalysts have a larger metal doped than ion-exchange, the latter show a higher stability and these catalysts therefore are selected during the processing of the different biomass.

TABLE 4 | Mass of water, carbon monoxide, and carbon dioxide determined by the FT-IR and the $\mathrm{H} / \mathrm{C}$ ratio for a sample of mass of approximately $20 \mathrm{mg}$.

\begin{tabular}{lccc}
\hline & $\begin{array}{c}\text { Pellet } \\
\text { cycle1 }\end{array}$ & $\begin{array}{c}\text { Pellet } \\
\text { cycle2 }\end{array}$ & $\begin{array}{c}\text { Pellet } \\
\text { cycle 3 }\end{array}$ \\
\hline Mass of water (mg) & 4.5 & 7.7 & 7.4 \\
Mass of carbon dioxide (mg) & 17.6 & 47.9 & 44.0 \\
Mass of carbon monoxide (mg) & 1.0 & 1.8 & 1.9 \\
Carbon wt.\% & 40.3 & 43.3 & 43.1 \\
Hydrogen wt.\% & 2.3 & 1.5 & 1.5 \\
H/C ratio & 1.1 & 1.5 & 0.7
\end{tabular}

\section{Processing of Biomass with Metal-Doped Zeolites}

This section gives a brief overview of the processing of sunflower oil, soy protein, and two microalgae Chlorella and the stressed $P$. ellipsoidea regarding the composition of the bio-crude oil. The stressed $P$. ellipsoidea contains a significant lipid content (67.0 wt.\%) and low ash content (less than 1.0 wt.\%). The lipid fraction was increased by starving the microalga for nitrogen nutrients as described in a previous study (Satoh et al., 2010). Soy protein is $90.0 \mathrm{wt} . \%$ pure with $3.5 \mathrm{wt} . \%$ of ash. Chlorella contains high protein content (55.0 wt.\%) and low lipids (25.0 wt.\%) and high ash content with 10.9 wt.\%. Sunflower oil is refined and contains mainly linoleic acid and oleic acid as fatty acids. Table 5 summarizes the main results, including the bio-crude yield (as dried basis), the elemental analysis, and the energy efficiency. The average coefficient of variance is approximately $6.5 \%$ for the bio-crude yield; $0.9-2.5 \%$ for the nitrogen content, and for the carbon, hydrogen, and sulfur content are listed with a coefficient of variance of approximately $2.0 \%$. In this study, results regarding the bio-crude composition are detailed; however, the initial biomass is degraded within different phases, including the aqueous, residue, and gaseous phases. The mass yield of these phases is included in Table S1 in Supplementary Material.

\section{Sunflower Oil}

The bio-crude yield (Table 5) was more significant for noncatalytic run compared to the run with metal-doped HZSM-5 implying that these catalysts enhanced the cracking of sunflower oil. For the processing of sunflower oil, no residue was produced. The mass of the gaseous yield was more significant for NiZSM-5, as nickel is known to promote gasification (Stucki et al., 2009). The mass of the aqueous phase is also more significant with the catalytic run from 22.8 to 36.4 wt.\%.

Between the two catalysts prepared by impregnation and ionexchange with molybdenum, higher activity was achieved with MoZSM-5 prepared with metal exchanged. HZSM-5 in the form of powder is more active with lower bio-crude yield and a higher fraction of aromatic compound produced. In general, there is a trade-off as the most robust catalyst has lower activity compared to the ion-exchanged catalysts.

The elemental analysis, in Table 5, indicates that HZSM-5 and MoZSM-5 enhance the deoxygenation for sunflower oil with low oxygen content with 7.7 and 8.8 wt.\%, respectively, compared to the run without any catalyst. Furthermore, these bio-crude oils have a close heating value close to the petroleum oil with 42-44 MJ/kg (Demirbaş, 1998). Higher decarboxylation from palmitic acid was observed in the previous study (Mo and Savage, 2014), since more catalysts and higher temperatures with supercritical water conditions were used.

The molecular weight distribution for different catalysts measured by GPC is included in Figure S4A in Supplementary Material. HZSM-5 contains in majority "long-chain" or fatty acid materials and the lowest fraction of oligomers materials compared to the other catalysts. Oligomers are produced from the cross-linked reaction between the linoleic and oleic acids. MoZSM-5 contains the highest fraction of lower molecular weight materials which could include aliphatic hydrocarbons 
TABLE 5 | Elemental composition and the bio-crude yield as received of the bio-crude oils using the different catalysts in water and the $\%$ of energy recovery.

\begin{tabular}{|c|c|c|c|c|c|c|c|c|}
\hline & N wt. $\%$ & C wt. $\%$ & H wt. $\%$ & S wt. $\%$ & O wt. $\%$ & Dulong HHV (MJ/kg) & Bio-crude yield wt. \% & $\%$ Energy recovery \\
\hline \multicolumn{9}{|c|}{ Sunflower oil } \\
\hline Raw & - & 72.9 & 11.1 & & 16.0 & 37.6 & - & - \\
\hline No catalyst & - & 76.8 & 11.5 & - & 11.7 & 40.3 & 86.0 & 92.3 \\
\hline HZSM-5 & - & 80.4 & 11.9 & - & 7.7 & 42.8 & 68.0 & 72.0 \\
\hline FeZSM-5 & - & 75.5 & 11.4 & - & 13.1 & 39.5 & 58.0 & 65.4 \\
\hline CuZSM-5 & - & 74.4 & 11.6 & - & 13.9 & 39.3 & 73.0 & 76.1 \\
\hline MoZSM-5 & - & 80 & 11.6 & - & 8.4 & 42.1 & 60.0 & 67.1 \\
\hline NiZSM-5 & - & 77.2 & 11.7 & - & 11.1 & 40.8 & 55.0 & 50.0 \\
\hline \multicolumn{9}{|l|}{ Soy protein } \\
\hline Raw & 14.2 & 50.6 & 7.4 & 0.4 & 27.4 & 22.8 & - & - \\
\hline No catalyst & 6.1 & 72.8 & 9.2 & 0.4 & 11.5 & 35.7 & 17.5 & 65.6 \\
\hline HZSM-5 & 7.5 & 71.5 & 9.7 & 0.6 & 10.7 & 36.1 & 10.8 & 28.9 \\
\hline FeZSM-5 & 6.6 & 70.5 & 9.5 & 0.7 & 12.8 & 35.2 & 15.1 & 19.8 \\
\hline CuZSM-5 & 7.8 & 79.1 & 10.5 & 0.7 & 1.9 & 41.5 & 14.0 & 30.3 \\
\hline MoZSM-5 & 5.7 & 67.6 & 9.3 & 0.5 & 16.9 & 33.2 & 15.1 & 15.1 \\
\hline NiZSM-5 & 7.3 & 75.7 & 9.9 & 0.9 & 6.3 & 38.7 & 15.0 & 30.3 \\
\hline \multicolumn{9}{|l|}{ Chlorella } \\
\hline Raw & 10.3 & 49.4 & 7.4 & 0.5 & 21.5 & 21.5 & - & - \\
\hline No catalyst & 5.9 & 74.9 & 9.3 & 0.6 & 9.4 & 36.9 & 28.9 & 50.3 \\
\hline HZSM-5 & 5.5 & 75.0 & 9.3 & 0.4 & 9.7 & 37.0 & 18.3 & 36.5 \\
\hline FeZSM-5 & 5.2 & 73.4 & 8.8 & 0.8 & 11.8 & 35.4 & 29.6 & 48.9 \\
\hline CuZSM-5 & 6.7 & 80 & 10.1 & 0.4 & 2.8 & 41.0 & 18.7 & 42.4 \\
\hline MoZSM-5 & 6.2 & 82.5 & 10.5 & 0.4 & 0.5 & 42.8 & 21.6 & 51.1 \\
\hline NiZSM-5 & 6.5 & 75.5 & 9.7 & 0.6 & 7.7 & 38.0 & 28.1 & 38.5 \\
\hline \multicolumn{9}{|c|}{ Stressed $P$. ellipsoidea } \\
\hline Raw & 2.9 & 63.4 & 9.5 & - & 30.6 & 30.6 & - & - \\
\hline No catalyst & 1.0 & 70.5 & 10.3 & - & 18.2 & 35.3 & 49.3 & 56.9 \\
\hline HZSM-5 & 2.1 & 78.0 & 11.7 & - & 8.1 & 41.7 & 25.5 & 35.8 \\
\hline FeZSM-5 & 1.6 & 75.2 & 11.3 & - & 11.9 & 39.4 & 34.2 & 33.9 \\
\hline CuZSM-5 & 2.2 & 81.5 & 11.9 & - & 4.5 & 43.7 & 22.8 & 33.7 \\
\hline MoZSM-5 & 2.2 & 80.4 & 11.2 & - & 6.2 & 42.1 & 34.2 & 46.2 \\
\hline NiZSM-5 & 1.5 & 74.6 & 11.0 & - & 12.9 & 38.6 & 33.5 & 47.7 \\
\hline
\end{tabular}

and aromatic compounds. The fraction of oligomers is more significant with CuZSM-5.

MoZSM-5 is more selective to produce aromatic compounds as these molecules identified with the GC-MS in the bio-crude oil: 1,3-ethyl-dimethyl-benzene, 1-methyl-butyl-benzene, 1,4-methyl-2-(2-methyl-propyl)-benzene, and decahydronaphthalene. It explains why more "low molecular weight materials" are observed for this catalyst. Aromatic compounds are produced from the Diels-Alder reaction (Benson et al., 2009). The biocrude oil for HZSM- 5 contains more alkenes compounds such as 8-heptadecene, 3-ethyl-2-pentene, and 4-undecene. Oxygenated compounds were also identified with a lower fraction compared to the other catalysts and the non-catalytic run. Oleic acid was the most abundant, followed by $Z, Z-10,12$-hexadecadienal which is produced from the degradation of linoleic acid.

Previous studies (Mo and Savage, 2014; Mo et al., 2015) demonstrated the formation of benzene, toluene, and xylene (BTX) compounds from fatty acids using HZSM- 5 in supercritical water. Nevertheless, a high fraction of coke and gas was obtained. In this study, only $2.5 \mathrm{wt} . \%$ of coke was produced and only 2 bar of gas was produced which represent approximately 5 wt.\% of mass yield. Furthermore, a ratio catalyst, feedstock of 1:1, was used which is not economically viable compared to $10 \mathrm{wt} . \%$ used in this study.

Therefore, HZSM-5, MoZSM-5, and NiZSM-5 have a good activity in processing sunflower oil into alkenes and aromatic compounds. CuZSM-5 enhanced the formation of oligomer materials in the bio-crude oil. Therefore, in this case, MoZSM-5 would be the most suitable catalyst to process sunflower oil to produce a bio-crude with less oxygen content.

\section{Soy Proteins}

At the opposite of the processing of sunflower oil, the majority of the soy protein at $350^{\circ} \mathrm{C}$ is degraded within the aqueous phase with approximately $73.1 \mathrm{wt} . \%$ of yield. In opposition to the previous section, low bio-crude yield (17.8 wt.\%) was produced, and the formation of residue is more important compared with the processing of sunflower oil. Furthermore, the addition of metal-doped HZSM-5 has a minor impact on enhancing the biocrude yield compared to sunflower oil. The lower bio-crude yield with catalyst could be explained that some compounds could be absorbed within the zeolite pores. MoZSM-5 was more selective to enhance the formation of gas with $21.5 \mathrm{wt} . \%$ (result in the Datasheet S1 in Supplementary Material). 
Elemental values (Table 5) indicate that the nitrogen content is significant in the bio-crude oil. A reduction in nitrogen is only achieved using MoZSM-5 (5.1 wt.\% with a coefficient of variance of $0.9 \%)$ compared to the non-catalytic run. Higher nitrogen content is measured with the other catalysts (with a coefficient of variance of $2.5 \%$ ). Interestingly, CuZSM-5 and NiZSM-5 with 1.9 and 6.3 wt.\% oxygen content, respectively, enhanced the deoxygenation capacity.

The formation of heavy molecular weight materials (with a molecular weight higher than $1000 \mathrm{~g} / \mathrm{mol}$ ) was enhanced with CuZSM-5 (Figure S4B in Supplementary Material). One previous study (Imai et al., 1999) suggests that $\mathrm{CuCl}_{2}$ enhances the oligomerization of glycine forming long peptide chain in hydrothermal vents in the bottom of the ocean. It could indicate here that the metal leachate present in the aqueous phase could enhance the condensation of small molecules into heavy molecular weight materials. The drawback is that the processed water produced during the HTL of microalgae should be recycled back for the cultivation of microalgae nevertheless metals such as copper and nickel inhibit their growth (Stucki et al., 2009).

The majority of compounds identified in the bio-crude oil by GC-MS are nitrogen heterocyclic molecules, for example, pyrazine, diisopropylpiperazine-2,5-dione, pyrrole, 1-butyl2-pyrrolidinone, 1-(1-oxo-9,12-octadecadienyl)-pyrrolidine, and 3-methyl- $1 H$-indole. The disadvantage of these molecules is that they are relatively stable.

For the catalytic run, more complex structures were identified with GC-MS within the bio-crude oil which include $N$-(1-methyl2-propynyl)-benzenamine, 1-(2-phenylethyl)-pyrimidine2,4,6trione, 5,10-diethoxy-2,3,7,8-tetrahydro-dipyrrolopyrazine, and hexahydro-3-(phenylmethyl)-pyrrolopyrazine-1,4-dione. The presence of L-leucine- $N$-cyclopropylcarbonyl-1-methyl ester $9 \mathrm{H}$-pyridoindole is one example of compounds produced from the condensation of several monomers which explains why with CuZSM-5 the fraction of oligomers and heavy molecular weight materials are more significant.

To conclude, metal-doped zeolites have lower impact on improving the formation of bio-crude yield. Nevertheless, MoZSM-5 reduced the nitrogen content and CuZSM-5 and NiZSM-5 enhanced the deoxygenation of the bio-crude oil. The drawback of CuZSM-5 is that more oligomers and heavy molecular weight materials are being formed. Therefore, the most efficient catalyst to process soy protein would be NiZSM-5 with a good conversion toward deoxygenation and the production of low molecular weight materials.

\section{Microalgae}

Microalgae are composed of various elements, including proteins, lipids, carbohydrates, and inorganic salts; it is the reason why the bio-crude oil has a complex composition. The initial content of the microalgae determines the bio-crude yield as follows: lipids $>$ proteins $>$ carbohydrates (Biller et al., 2011). Therefore, it explains why the higher bio-crude yield was achieved at $350^{\circ} \mathrm{C}$ for the stressed P. ellipsoidea with 49.3 wt.\% compared to Chlorella with 28.9 wt.\% containing a higher protein content.
Similar to the catalytic processing of soy protein and sunflower oil, the bio-crude yields are lower compared to the non-catalytic run, this is especially observed with the stressed $P$. ellipsoidea. In general, not only FeZSM-5 but also NiZSM-5 (with lower extent) enhance the bio-crude yield compared to the other catalysts, especially with Chlorella (29.6 wt.\%) which is higher than the non-catalytic run. Similarly with soy protein, the formation of gas was more significant with MoZSM-5 particularly with Chlorella with approximately 49.3 wt.\%. Molybdenum is also known to promote gasification (Elliott et al., 2006).

As previously earlier, for the stressed $P$. ellipsoidea, the nitrogen content values (from 2.1 to $1.5 \mathrm{wt}$ \% with a coefficient of variance of $2.0 \mathrm{wt} . \%$ ) are particularly higher compared to the non-catalytic run (1.0 wt.\% with a coefficient of variance of 2.5 wt.\%). For Chlorella, HZSM-5 and MoZSM-5 reduce slightly the nitrogen content within the bio-crude oil, nevertheless as previously discussed the catalyst has minor impact on the nitrogen content. A slight increase in nitrogen content within the bio-crude using a "zeolite" was observed compared to the non-catalytic run for the processing of Nannochloropsis (Duan and Savage, 2010).

More significant results were observed with deoxygenation especially using MoZSM-5 and Chlorella with an oxygen content of 0.5 wt.\%. Similar oxygen content values were already obtained pretreating a bio-crude oil with HZSM-5 at higher temperature and time at $500^{\circ} \mathrm{C}$ and $4 \mathrm{~h}$ and $5 \mathrm{wt} . \%$ loading or using $50 \mathrm{wt} . \%$ for half an hour at the same temperature (Li and Savage, 2013). Therefore, it is an encouraging result implying that lower harsh conditions could be used with less catalyst loading. The most efficient energy recovery is determined using NiZSM-5 with a good deoxygenation.

The GPC results of the processing of Chlorella for FeZSM-5 and NiZSM-5 (Figure S4C in Supplementary Material) exhibit larger fractions of oligomers and "heavy molecular weight" materials. Conversely, CuZSM-5 and HZSM-5 result in increased yields of lower molecular weight materials. The presence of catalyst did not have a significant impact on the level of "long-chain" materials which remains constant. For the processing of the stressed P. ellipsoidea (Figure S4D in Supplementary Material), the "long-chain" material is the highest fraction since this alga contains $67.0 \mathrm{wt} . \%$ dry weight lipids. MoZSM-5, in water, enhances the formation of "heavy molecular weight" materials.

The bio-crude oil is composed of nitrogen heterocyclic compounds similar to the bio-crude from soy protein processing. Figure 4 shows two examples of GC-MS chromatogram, where Figure 4A shows the non-catalytic run and Figure $4 \mathrm{~B}$ shows the MoZSM-5.

The chromatogram (B) contains less compared to the noncatalytic run. Amide fatty acids and hydrocarbon molecules are also identified because of the initial presence of lipids. The processing with the metal-doped zeolite, for example, with MoZSM-5 and Chlorella produces lower oxygenated compounds including 2-butylhexanoic acid and 3-pentyloxycarbonylpropyl ester with more hydrocarbons such as 3-octadecene and hexadecane. Complex nitrogen compounds are also identified, such as 1-ethyl-2-undecylimidazole in the bio-crude oil of CuZSM-5. It is also observed that the presence of amide fatty acids is reduced 

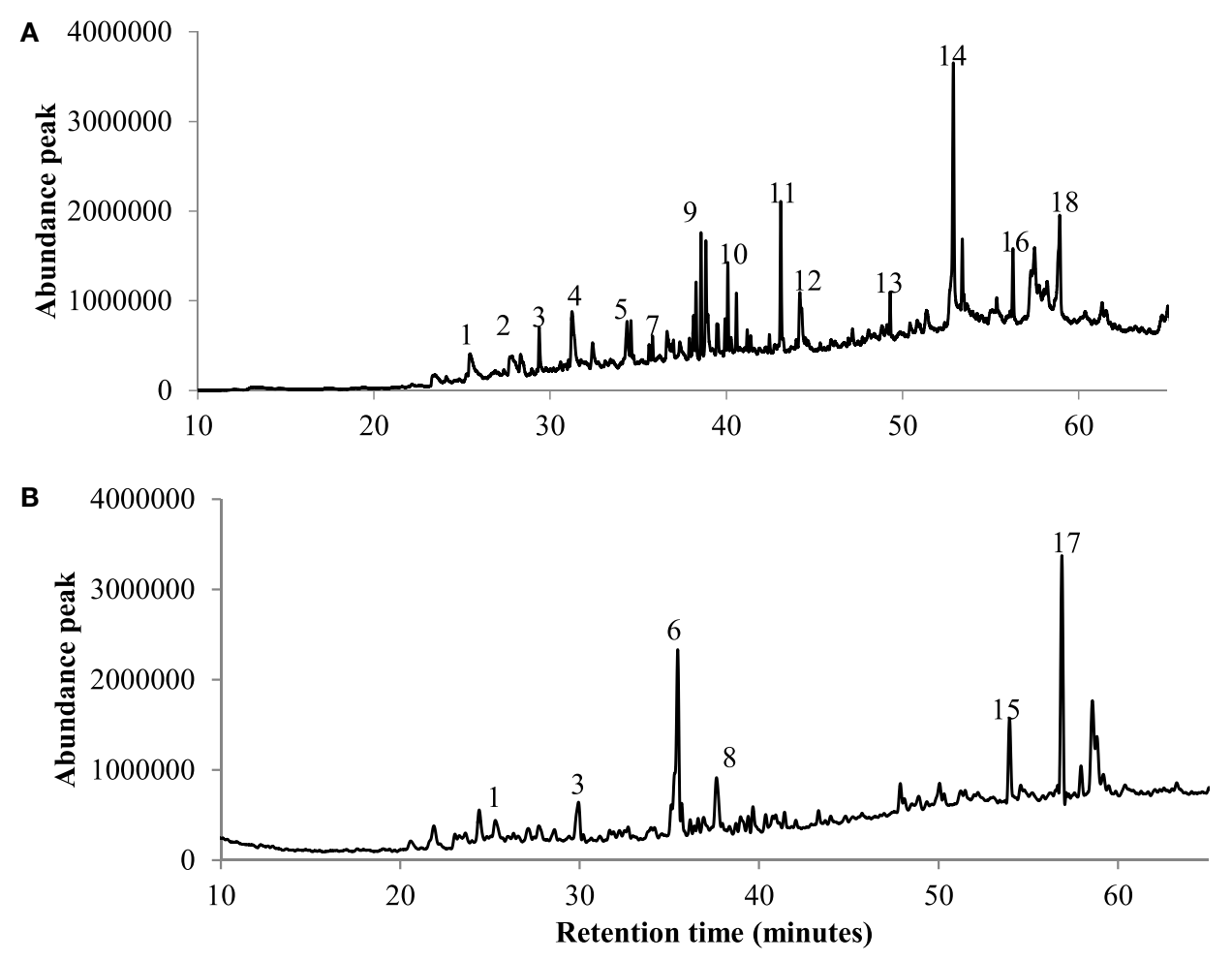

FIGURE 4 | GC-MS chromatogram of the bio-crude oils at $350^{\circ} \mathrm{C}$ processing Chlorella, where (A) shows the non-catalytic run and (B) shows the MoZSM-5. (1) 25.4 min 4-methyl-phenol; (2) 27.8 min 3-ethyl-phenol; (3) 29.4 min hexadecane; (4) 31.7 min 1-butyl-2-pyrrohdinone; (5) 34.3 min 3-methyl-indole; (6) 35.4 min 3-octadecene; (7) 36.6 min benzonitrile; (8) 37.6 min 2,3-dihydro-1-methyl-1H-pyrrole; (9) 38.3 min 3,7,1 I,15-tetramethyl-2-hexadecene; (10) 40.5 min 7-hexadecyn-1-ol; (11) 43.1 min isophytol; (12) 44.1 min ethyl-phenyl-piperidine; (13) 49.1 min 1-nonadecene; (14) 52.8 min hexadecademide; (15) 53.8 min 9-octadecenamide; (16) 53.6 min (5-amino-thiadiazol-2-yl)-propyl-3H-benzooxazol-2-one; (17) 56.3 min 2-butylhexanoic acid, 3-pentyloxycarbonylpropyl ester; (18) 58.8 min octanoic acid, morpholide.

compared to the other catalysts as copper could enhance the hydrolysis of amides (Dzumakaev et al., 1986). For the stressed P. ellipsoidea, more alkene and amides were identified within the bio-crude oil. Lower heterocyclic compounds are identified, such as pyrrole.

Overall, an efficient deoxygenation is achieved for MoZSM-5 with Chlorella; CuZSM-5 and NiZSM-5 generally enhanced the formation of bio-crude oil with lower oxygen content. Even though a slight reduction in nitrogen content was observed for MoZSM-5, on the whole, metal-doped zeolite had low impact on the denitrogenation. In subcritical water, the activity of catalyst depends on the biomass processed with less side reaction, for example, MoZSM-5 would be more efficient with sunflower oil. A good deoxygenation is achieved with CuZSM-5 but when high protein content is processed, although the formation of oligomers and heavy molecular weight materials is more significant.

\section{DISCUSSION}

Comparing pyrolysis condition, HZSM-5 has a lower activity converting biomass feedstock (Idem et al., 1997; ThangalazhyGopakumar et al., 2012), nevertheless in subcritical water, HZSM-5 is more selective to produce long-chain materials, which make more suitable for jet fuel or kerosene-like fuel and produce less coke.

The low metal loading on HZSM-5 had a significant impact on the stability and the processing of different biomass feedstock. Nevertheless, the method to insert the metal should be improved in order to increase the metal loading first, and second to reduce the leaching during subcritical water. For example, the stability and also the performance of doped metal HZSM-5 could be improved further using phosphorus (from phosphoric acid) (Xue et al., 2007). Bimetallic doping should be investigated to enhance the catalytic activity of HZSM-5, for example, the combination of molybdenum and copper could reduce the deactivation and increase the stability of the catalyst. Moreover, SAPO catalysts seem to be a good candidate to upgrade biomass due to the high stability under hydrothermal condition and wider pore sizes (Mees et al., 2003).

In this study, doped metal HZSM-5 demonstrated to have a lower impact on the denitrogenation. In literature, harsh conditions (temperature higher to $500^{\circ} \mathrm{C}$ and using hydrogen) are required to lower nitrogen content, although approximately 2.0 wt. $\%$ of nitrogen content are still present in the upgrading bio-crude (Duan et al., 2013; Bai et al., 2014). Therefore, one of the solutions would be to employ zeolites as molecular sieves to 
reduce the nitrogen content. Doped HY with copper or zeolite-A was previously used as an absorbent for heterocyclic nitrogen compounds. Even with low activity, these zeolites could be used in higher proportion to reduce the amount of heteroatoms (nitrogen and oxygen) in the bio-crude oils (Liu et al., 2008; Xia et al., 2015). Nitrogen compounds found in the bio-crude of soy protein, for example, including 1,3-bis(2-phenylethyl) pyrimidine-2,4,6(1H,3H,5H)-trione, could be extracted and used as high-value molecules which can be used as drug therapy (Xia et al., 2015).

Finally, as in this study, catalysts reduced the formation of biocrude yield to some extent. It would imply that more raw feedstock biomasses are necessary to obtain sufficient oil to produce a high-quality fuel; it is the reason why it could be economically more viable to use a microalgal strain containing a high lipid content such as with $P$. ellipsoidea.

\section{CONCLUSION}

Subcritical water conditions did have some influence on the physical properties due to abrasion, but less influence on the chemical structure of HZSM-5. Less leaching occurred for nickel compared to molybdenum. The doped metal HZSM-5 had enhanced stability, for example, molybdenum with HZSM-5 improved crystallinity, and copper improved the surface area. Finally, ion-exchange HZSM-5 seemed to produce a more stable form than the impregnated catalyst. HZSM-5 was processed with sunflower oil four times. It was found that the coke amount increased after each test, resulting in the decreased surface area. In general, the bio-crude yield was lower adding the catalyst compared to the non-catalytic run. CuZSM-5 and NiZSM-5 had

\section{REFERENCES}

Bai, X., Duan, P., Xu, Y., Zhang, A., and Savage, P. E. (2014). Hydrothermal catalytic processing of pretreated algal oil: a catalyst screening study. Fuel 120, 141-149. doi:10.1016/j.fuel.2013.12.012

Benson, T. J., Hernandez, R., French, W. T., Alley, E. G., and Holmes, W. E. (2009). Elucidation of the catalytic cracking pathway for unsaturated mono-, di-, and triacylglycerides on solid acid catalysts. J. Mol. Catal. A Chem. 303, 117-123. doi:10.1016/j.molcata.2009.01.008

Biller, P., Friedman, C., and Ross, A. B. (2013). Hydrothermal microwave processing of microalgae as a pre-treatment and extraction technique for bio-fuels and bio-products. Bioresour. Technol. 136, 188-195. doi:10.1016/j. biortech.2013.02.088

Biller, P., Riley, R., and Ross, A. B. (2011). Catalytic hydrothermal processing of microalgae: decomposition and upgrading of lipids. Bioresour. Technol. 102, 4841-4848. doi:10.1016/j.biortech.2010.12.113

Biller, P., and Ross, A. B. (2011). Potential yields and properties of oil from the hydrothermal liquefaction of microalgae with different biochemical content. Bioresour. Technol. 102, 215-225. doi:10.1016/j. biortech.2010.06.028

Corbitt, R. A. (1999). Standard Handbook of Environmental Engineering. Washington, DC: McGraw-Hill.

Corma, A., Huber, G., Sauvanaud, L., and Oconnor, P. (2007). Processing biomass-derived oxygenates in the oil refinery: catalytic cracking (FCC) reaction pathways and role of catalyst. J. Catal. 247, 307-327. doi:10.1016/j. jcat.2007.01.023

de Lucas, A., Canizares, P., Duran, A., and Carrero, A. (1997a). Coke formation, location, nature and regeneration on dealuminated HZSM- 5 type zeolites. Appl. Catal. A. Gen. 156, 299-317. doi:10.1016/S0926-860X(97)00045-8 good catalytic activities to reduce the oxygen content during the processing of soy protein and microalgae. MoZSM-5 enhanced the formation of aromatic compounds from sunflower oil. An encouraging result was observed with MoZSM-5 and Chlorella, as the oil had a lower oxygen content. Some further investigations are required to improve the stability and activity of metal zeolites for the purpose of upgrading biomass in subcritical water.

\section{AUTHOR CONTRIBUTIONS}

I hereby TR declare that I carried out all the experiments and measurements except for the STEM measurement by Dr. Nicole Hondow. I have written the manuscript. Dr. AL-L helped me in the analysis of my sample with the XRD and the STEM, she also proofreaded my manuscript. Dr. AR was my main supervisor and supervised the experiments. Prof. JJ was my second supervisor and she helped me in the planification of experiments.

\section{ACKNOWLEDGMENTS}

The authors would like to thank the Engineering and Physical Sciences Research Council for financial support (EP/I014365/1). In addition, the authors are grateful not only to Simon Lloyd and Dr. Adrian Cunliff for technical support but also to Dr. Tim Comyn for the XRD, Dr. Leilani Darvell for the STA-FTIR, and Dr. Nicole Hondow for STEM measurement.

\section{SUPPLEMENTARY MATERIAL}

The Supplementary Material for this article can be found online at http://journal.frontiersin.org/article/10.3389/fenrg.2015.00051

de Lucas, A., Canizares, P., Durán, A., and Carrero, A. (1997b). Dealumination of HZSM-5 zeolites: effect of steaming on acidity and aromatization activity. Appl. Catal. A Gen. 154, 221-240. doi:10.1016/s0926-860x(96)00367-5

Demirbaş, A. (1998). Fuel properties and calculation of higher heating values of vegetable oils. Fuel 77, 1117-1120. doi:10.1016/S0016-2361(97)00289-5

Duan, P., Bai, X., Xu, Y., Zhang, A., Wang, F., Zhang, L., et al. (2013). Catalytic upgrading of crude algal oil using platinum/gamma alumina in supercritical water. Fuel 109, 225-233. doi:10.1016/j.fuel.2012.12.074

Duan, P., and Savage, P. E. (2010). Hydrothermal liquefaction of a microalga with heterogeneous catalysts. Ind. Eng. Chem. Res. 50, 52-61. doi:10.1021/ie100758s

Dzumakaev, K. K., Kagarlitskii, A., and Fedolyak, G. (1986). Kinetics of benzonitrile hydration on a skeletal copper catalyst. React. Kinet. Catal. Lett. 30, 289-295. doi:10.1007/BF02064305

Elliott, D. C., Hart, T. R., and Neuenschwander, G. G. (2006). Chemical processing in high-pressure aqueous environments. 8. Improved catalysts for hydrothermal gasification. Ind. Eng. Chem. Res. 45, 3776-3781. doi:10.1021/ ie060031o

Flanigen, E. M., Jansen, J. C., and Van Bekkum, H. (1991). Introduction to Zeolite Science and Practice (Studies in Surface Science and Catalysis). Vol. 58, Elsevier Science.

Fu, J., Lu, X., and Savage, P. E. (2010). Catalytic hydrothermal deoxygenation of palmitic acid. Energy Environ. Sci. 3, 311-317. doi:10.1039/b923198f

Gayubo, A. G., Aguayo, A. T., Atutxa, A., Prieto, R., and Bilbao, J. (2004a). Deactivation of a HZSM-5 zeolite catalyst in the transformation of the aqueous fraction of biomass pyrolysis oil into hydrocarbons. Energy Fuels 18, 1640-1647. doi:10.1021/ef040027u

Gayubo, A. G., Aguayo, A. T., Atutxa, A., Prieto, R., and Bilbao, J. (2004b). Role of reaction-medium water on the acidity deterioration of a HZSM-5 zeolite. Ind. Eng. Chem. Res. 43, 5042-5048. doi:10.1021/ie0306630 
Gayubo, A. G., Alonso, A., Valle, B., Aguayo, A. T., Olazar, M., and Bilbao, J. (2010). Hydrothermal stability of HZSM-5 catalysts modified with Ni for the transformation of bioethanol into hydrocarbons. Fuel 89, 3365-3372. doi:10.1016/j. fuel.2010.03.002

Idem, R. O., Katikaneni, S. P. R., and Bakhshi, N. N. (1997). Catalytic conversion of canola oil to fuels and chemicals: roles of catalyst acidity, basicity and shape selectivity on product distribution. Fuel Process. Technol. 51, 101-125. doi:10.1016/s0378-3820(96)01085-5

Imai, E.-I., Honda, H., Hatori, K., Brack, A., and Matsuno, K. (1999). Elongation of oligopeptides in a simulated submarine hydrothermal system. Science 283, 831-833. doi:10.1126/science.283.5403.831

Li, Z., and Savage, P. E. (2013). Feedstocks for fuels and chemicals from algae: treatment of crude bio-oil over HZSM-5. Algal Res. 2, 154-163. doi:10.1016/j. algal.2013.01.003

Liu, D., Gui, J., and Sun, Z. (2008). Adsorption structures of heterocyclic nitrogen compounds over $\mathrm{Cu}$ (I) Y zeolite: a first principle study on mechanism of the denitrogenation and the effect of nitrogen compounds on adsorptive desulfurization. J. Mol. Catal. A Chem. 291, 17-21. doi:10.1016/j.molcata.2008.05.014

Long, R. Q., and Yang, R. T. (2000). Superior ion-exchanged ZSM-5 catalysts for selective catalytic oxidation of ammonia to nitrogen. Chem. Commun. 17, 1651-1652. doi:10.1039/b004957n

Mees, F., Martens, L., Janssen, M., Verberckmoes, A., and Vansant, E. (2003). Improvement of the hydrothermal stability of SAPO-34. Chem. Commun. 1, 44-45. doi:10.1039/b210337k

Mo, N., and Savage, P. E. (2014). Hydrothermal catalytic cracking of fatty acids with HZSM-5. ACS Sustain Chem Eng 2, 88-94. doi:10.1021/sc400368n

Mo, N., Tandar, W., and Savage, P. E. (2015). Aromatics from saturated and unsaturated fatty acids via zeolite catalysis in supercritical water. J. Supercrit. Fluids 102, 73-79. doi:10.1016/j.supflu.2015.03.018

Ortega, J. M., Gayubo, A. G., Aguayo, A. T., Benito, P. L., and Bilbao, J. (1997). Role of coke characteristics in the regeneration of a catalyst for the MTG process. Ind. Eng. Chem. Res. 36, 60-66. doi:10.1021/ie9507336

Peterson, A. A., Vogel, F., Lachance, R. P., Froling, M., Antal, J. M. J., and Tester, J. W. (2008). Thermochemical biofuel production in hydrothermal media: a review of sub- and supercritical water technologies. Energy Environ. Sci. 1, 32-65. doi:10.1039/b810100k

Pieterse, J. A. Z., Pirngruber, G. D., Van Bokhoven, J. A., and Booneveld, S. (2007). Hydrothermal stability of Fe-ZSM- 5 and Fe-BEA prepared by wet ion-exchange for N2O decomposition. Appl. Catal. B Environ. 71, 16-22. doi:10.1016/j. apcatb.2006.08.011

Pollack, S., Adkins, J., Wetzel, E., and Newbury, D. (1984). SiO2Al2O3 ratios of ZSM - 5 crystals measured by electron microprobe and X-ray diffraction. Zeolites 4, 181-187. doi:10.1016/0144-2449(84)90058-7

Ravenelle, R. M., Schüßler, F., D’amico, A., Danilina, N., Van Bokhoven, J. A., Lercher, J. A., et al. (2010). Stability of zeolites in hot liquid water. J. Phys. Chem. C 114, 19582-19595. doi:10.1021/jp104639e

Sano, T., Uno, Y., Wang, Z. B., Ahn, C. H., and Soga, K. (2000). Erratum to: realumination of dealuminated HZSM- 5 zeolites by acid treatment and their catalytic properties [Microporous and Mesoporous Materials 31 (1999) 89-95]. Microporous Mesoporous Mater. 34, 348. doi:10.1016/s1387-1811(99)00284-x

Sato, S., Yu-U, Y., Yahiro, H., Mizuno, N., and Iwamoto, M. (1991). Cu-ZSM-5 zeolite as highly active catalyst for removal of nitrogen monoxide from emission of diesel engines. Appl. Catal. 70, L1-L5. doi:10.1016/S0166-9834(00)84146-9

Satoh, A., Kato, M., Yamato, K., Ishibashi, M., Sekiguchi, H., Kurano, N., et al. (2010). Characterization of the lipid accumulation in a new microalgal species, Pseudochoricystis ellipsoidea (Trebouxiophyceae). J. Jpn. Inst. Energy 89, 909-913. doi:10.3775/jie.89.909

Song, Y., Sun, C., Shen, W., and Lin, L. (2006). Hydrothermal post-synthesis of HZSM-5 zeolite to enhance the coke-resistance of Mo/HZSM-5 catalyst for methane dehydroaromatization. Catal. Lett. 109, 21-24. doi:10.1007/ s10562-006-0066-2

Song, Y., Sun, C., Shen, W., and Lin, L. (2007). Hydrothermal post-synthesis of HZSM-5 zeolite to enhance the coke-resistance of Mo/HZSM-5 catalyst for methane dehydroaromatization reaction: reconstruction of pore structure and modification of acidity. Appl. Catal. A Gen. 317, 266-274. doi:10.1016/j. apcata.2006.10.037

Stucki, S., Vogel, F., Ludwig, C., Haiduc, A. G., and Brandenberger, M. (2009). Catalytic gasification of algae in supercritical water for biofuel production and carbon capture. Energy Environ. Sci. 2, 535-541. doi:10.1039/b819874h

Thangalazhy-Gopakumar, S., Adhikari, S., Chattanathan, S. A., and Gupta, R. B. (2012). Catalytic pyrolysis of green algae for hydrocarbon production using H+ ZSM-5 catalyst. Bioresour. Technol. 118, 150-157. doi:10.1016/j. biortech.2012.05.080

Xia, R., Na, D., Zhang, Y., Baoming, L., Zhidan, L., and Haifeng, L. (2015). Nitrogen and phosphorous adsorption from post-hydrothermal liquefaction wastewater using three types of zeolites. Int. J. Agric. Biol. Eng. 8, 86-95. doi:10.3965/j. ijabe.20150805.1561

Xue, N., Chen, X., Nie, L., Guo, X., Ding, W., Chen, Y., et al. (2007). Understanding the enhancement of catalytic performance for olefin cracking: hydrothermally stable acids in P/HZSM-5. J. Catal. 248, 20-28. doi:10.1016/j. jcat.2007.02.022

Yang, C., Jia, L., Chen, C., Liu, G., and Fang, W. (2011). Bio-oil from hydro-liquefaction of Dunaliella salina over Ni/REHY catalyst. Bioresour. Technol. 102, 4580-4584. doi:10.1016/j.biortech.2010.12.111

Conflict of Interest Statement: The authors declare that the research was conducted in the absence of any commercial or financial relationships that could be construed as a potential conflict of interest.

Copyright (C) 2015 Robin, Ross, Lea-Langton and Jones. This is an open-access article distributed under the terms of the Creative Commons Attribution License (CC BY). The use, distribution or reproduction in other forums is permitted, provided the original author(s) or licensor are credited and that the original publication in this journal is cited, in accordance with accepted academic practice. No use, distribution or reproduction is permitted which does not comply with these terms. 